\title{
Edificios de culto y prácticas religiosas en Chipre durante el Bronce Reciente (I)
}

\author{
Carmen Poyato holgado*
}

En la isla de Chipre se conoce un gran número de santuarios (Mapa 1), cuya construcción se inicia en el Chipriota Reciente II (1475-1225 a.C.) con la aparición de los "santuarios" de Ayios lakovos, Myrtou-Pighades (fase 3) y Kition (templos 2 y 3), en tanto que algo más tardiamente, en una etapa transicional, se fundan los santuarios de MaaPalaeokastro y Pyla-Kokkinokremos, cuya construcción tuvo lugar probablemente en la segunda mitad del siglo XIII a.C. Será durante el Chipriota Reciente III cuando la arquitectura religiosa de la isla adquiera una mayor importancia, ya que se fundan nuevos santuarios - Ayia Irini, Idalion, Palaepaphos y Enkomi- o se modifican los más antiguos, tal como sucede en Myrtou-Pighades, o se reestructuran y amplian las áreas de culto hasta formar un conjunto de notable importancia, tal como acontecerá en Kition.

En líneas generales, los santuarios chipriotas presentan algunas analogias entre sí, pero existen notables diferencias que se acentúan cuando se analiza su posición respecto a las áreas de asentamiento, asi como las diferentes estructuras internas y objetos de culto localizados en los edificios. Respecto a la posición que ocupan los "santuarios" o edificios de culto en relación a las áreas urbanas, hay que señalar que, al igual que sucede en Creta, Grecia Continental o las Cícladas (B. Rutkowski,

- Departamento de Prehistoria y Arqueología. Universidad Autónoma. Madrid. 


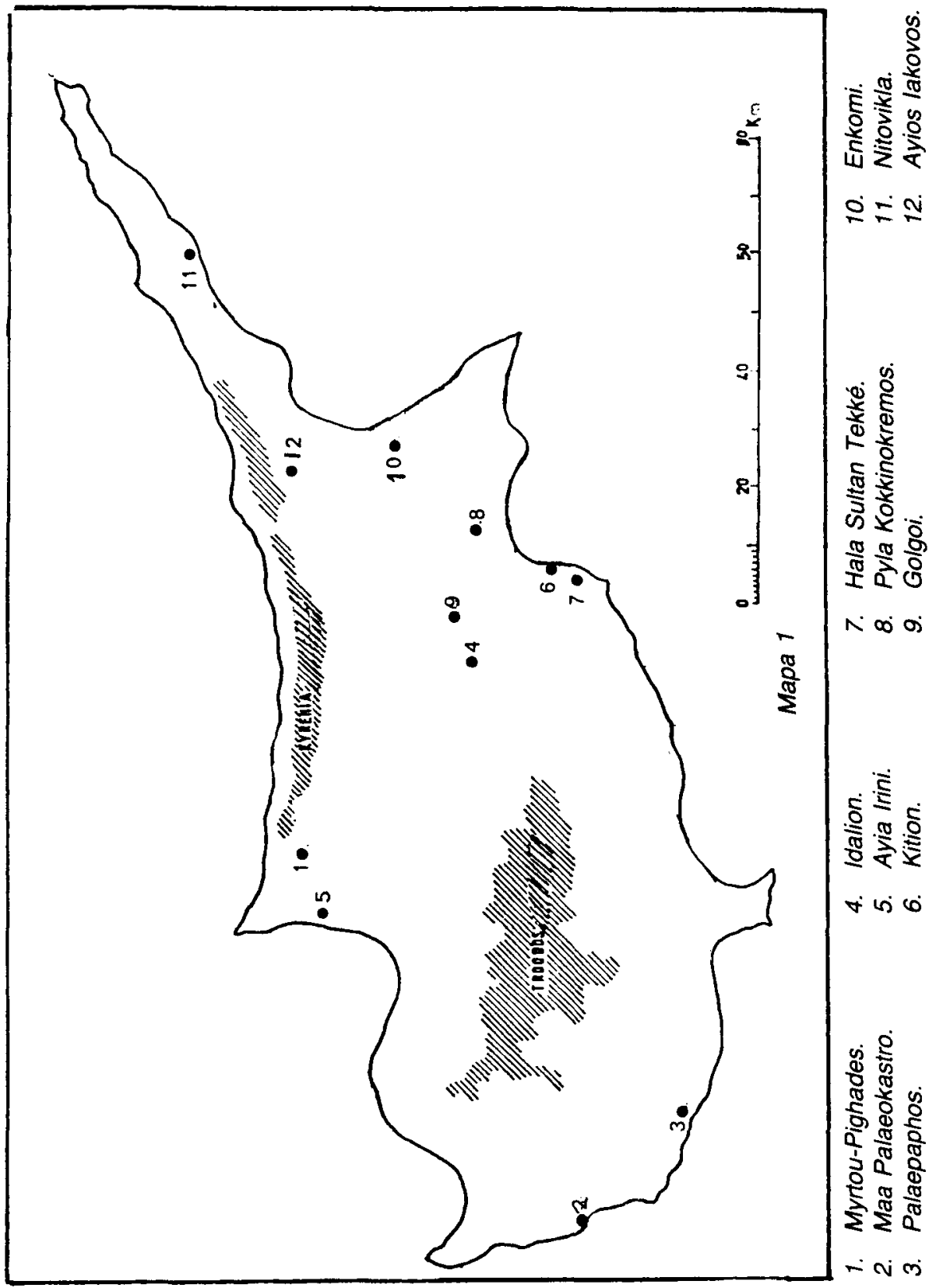


1986, G. C. Gessell, 1985), en Chipre estos edificios se encuentran habitualmente en las mismas posiciones:

1. Alejados de las áreas urbanas, constituyendo un grupo de «santuarios aislados", tales como Ayia Irini y Ayios lakovos.

2. "Santuarios Urbanos", constituyendo un grupo mucho más numeroso, en el que se aprecian varios subgrupos:

2.1. Santuarios formados por un único edificio, entre los cuales hay dos variantes:

2.1.A. Tan sólo cuentan con un edificio, que puede tener o no con varias habitaciones subsidiarias. En este grupo se integran los templos de Maa-Palaeokastro, Pyla-Kokkinokremos y Palaepaphos.

2.1.B. Santuarios constituidos por una o varias cellae y por una serie de edificios anejos subsidiarios, e incluso con otras dependencias en algunos casos. En este grupo se sitúan los complejos de Idalion y Myrtou-Pighades.

2.2. "Áreas de Culto", integradas por varios santuarios agrupados en una única zona del asentamiento, tal como sucede en Kition, el único caso de este tipo de complejos excavado hasta la fecha en la isla de Chipre.

2.3. Santuarios urbanos que además están perfectamente imbricados en las unidades domésticas del asentamiento, caso de los diferentes santuarios excavados en Enkomi.

Cada uno de los grupos, subgrupos y variantes, muestra características especiales que requieren un análisis más pormenorizado, tanto en lo que se refiere a su arquitectura como en lo que respecta a los dispositivos y parafernalia de culto que en ellos se han localizado.

\section{LOS SANTUARIOS "AISLADOS"}

Tanto Ayios lakovos (P. Astrom, 1972:1 y ss.; V. Karageorghis, 1982: 69; E. Gjerstad et Al., 1934: 359 y ss.) como Ayia Irini (P. Astrom, 1972: 1-4; E. Gjerstad et Al, 1935: 666 y ss.), situados ambos en el norte de la isla (Mapa 1), están alejados de cualquier asentamiento, pese a que se han buscado los poblados con gran interés, lo que les confiere un carác- 
ter particular en el conjunto de edificios de culto chipriotas. Las plantas de ambos edificios son completamente diferentes, ya que Ayios lakovos es un recinto de planta aproximadamente circular (fig. 2), en tanto que Ayia Irini está formado por una capilla -con dos habitaciones - y algunos edificios subsidiarios, todos ellos de planta rectangular (fig. 1).

En los dos santuarios se registra la presencia de un "patio" o espacio abierto, aunque de concepción y distribución diferentes. En Ayia Irini se trata de un amplio recinto, cuyos límites no están bien definidos, situado delante del "santuario», y separado del mismo mediante un muro que oculta la entrada a la capilla (fig. 1,5). En Ayios lakovos, el espacio abierto (fig. 2,2), en este caso una zona supuestamente sin techar, está situada al este de un murete de mampostería que la separa de la cella, donde se encuentran dos plataformas o podia. En ambos casos, es probable que las cellae, quedaran ocultas a la vista de los individuos con-

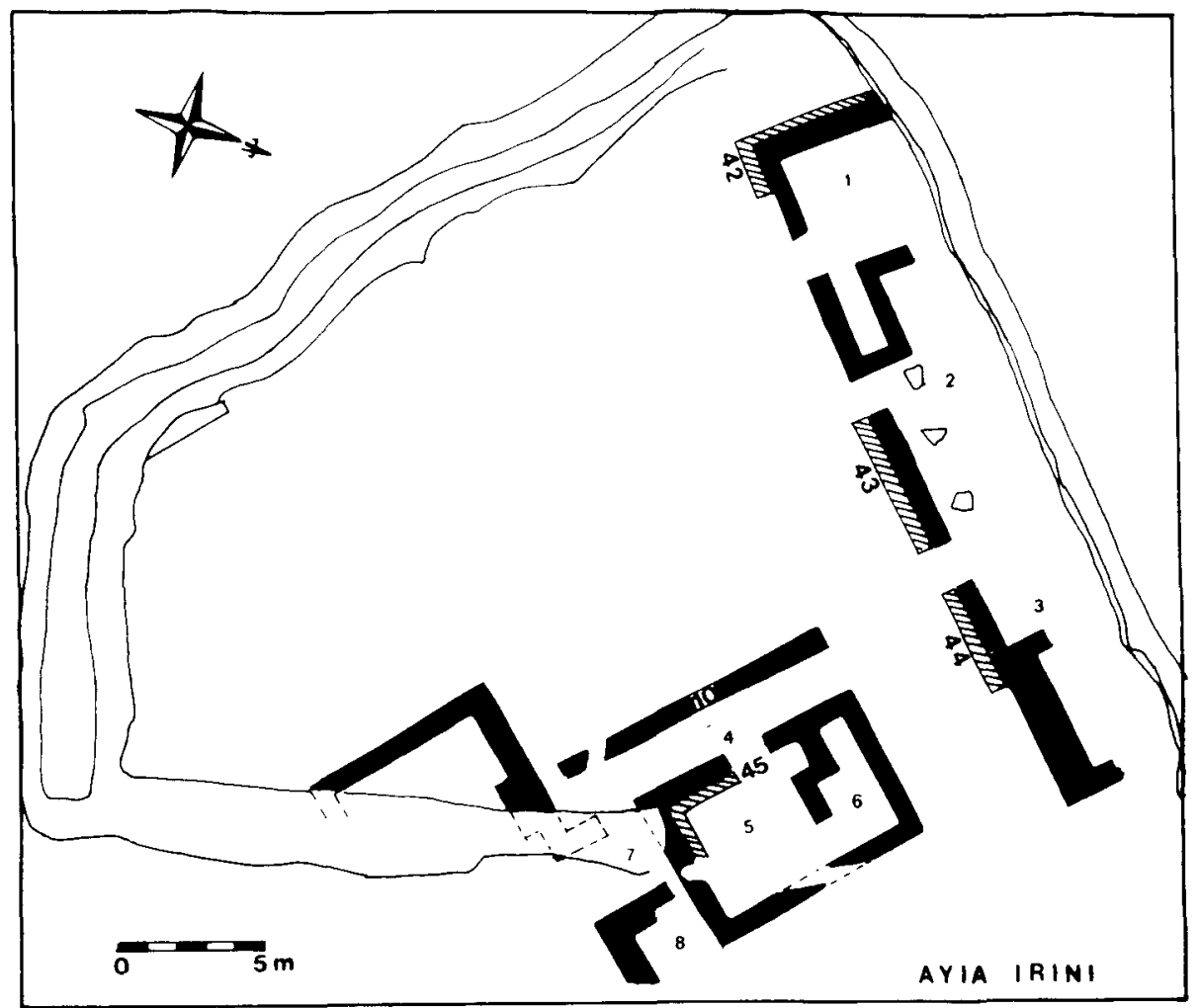

Fig. 1 


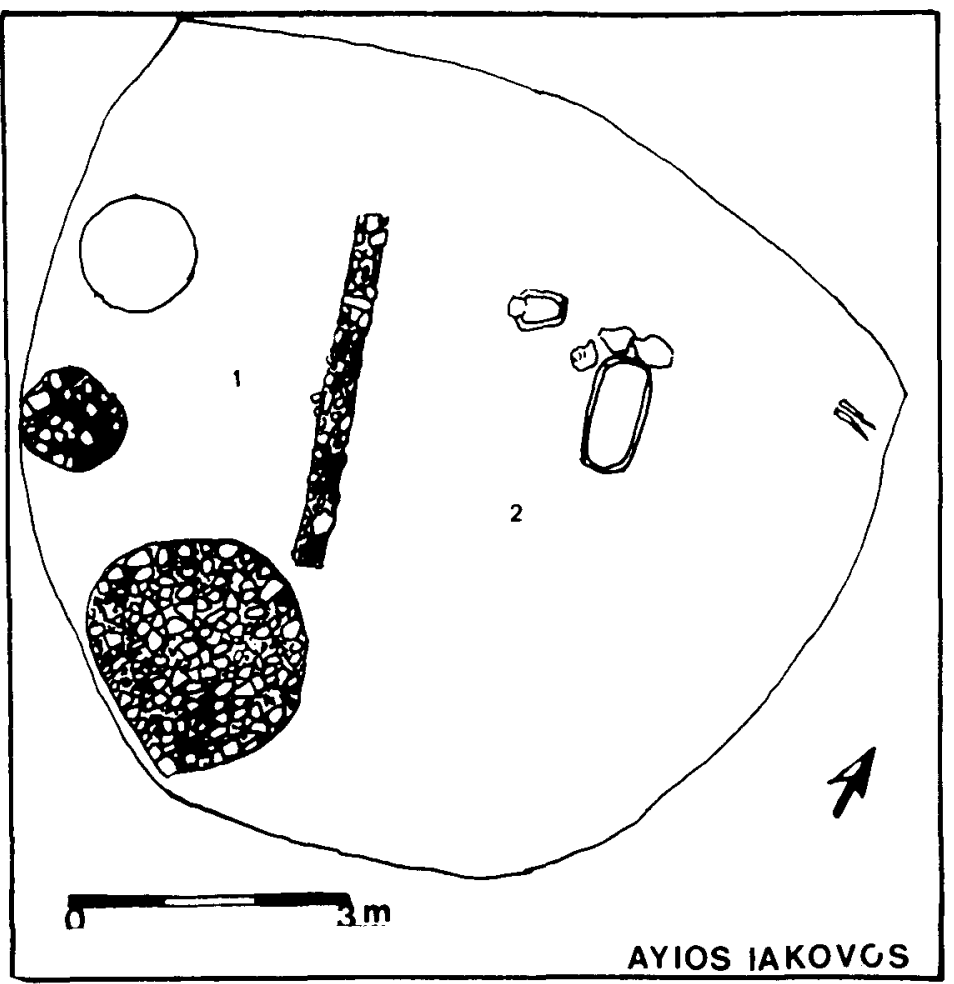

Fig. 2

gregados durante las ceremonias, siguiendo el modelo conocido en otros lugares del Egeo y el Próximo Oriente.

El «santuario" de Ayia Irini está construido con muros de zócalos de mampostería y alzados de adobe, en tanto que, en Ayios lakovos, el recinto sagrado estaba delimitado mediante una especie de empalizada de postes de madera, de la que no se conservaban evidencias materiales ya que, en realidad, se delimitó su planta en base a la extensión del pavimento de arcilla y guijarros.

Las estructuras internas de carácter ritual excavadas en ambos yacimientos son bastante limitadas, pero ofrecen algunas particularidades. En Ayios lakovos se han excavado dos plataformas (podia) (fig. 2, 1) de planta circular, construidas con mamposteria, que se han interpretado como altares, y varios bothroi o fosas excavadas en el suelo, en el "pa- 
tio", en uno de los cuales estaba incrustado un larnax de cerámica, liso, que al igual que los restantes pozos, apareció relleno de cenizas y con algunos restos de ofrendas de diferentes tipos. En Ayia Irini no se han localizado ni plataformas ni bothroi, pero destaca la presencia de un banco corrido que ocupa el ángulo SE de la "capilla" (fig. 1, 5), delante del cual había un hogar no estructural (cenizas y materia carbonizada únicamente), donde quizá debieron quemarse las ofrendas. La presencia de este banco corrido permite relacionar el santuario con los denominados "Santuarios con Banco", conocidos en Creta desde el III milenio, aunque adquieren su mayor desarrollo en el Minoico Reciente y el Postpalatial (G. C. Gessell, 1985: 19-22; 41-47). Otros bancos corridos están adosados al paramento exterior de los muros del llamado Edificio Norte (fig. 1, 42-44) recordando, por su disposición, los excavados en otro santuario chipriota: Myrtou-Pighades.

Los objetos rituales y votivos son también escasos aunque destaca la presencia de una "mesa de ofrendas", en realidad una gran laja de piedra rectangular, depositada en una pequeña habitación adyacente a la cella, junto con una figurita de bóvido, varios guijarros de diferentes colores y tamaños, un hacha de piedra pulimentada, algunas molederas y husos, también de piedra, puntas de flecha y varios recipientes cerámicos (pithoi), cuencos etc...) que fechan el período de uso del edificio en el Chipriota Reciente III. En Ayios lakovos, los materiales votivos son mucho más limitados, ya que tan sólo destaca la presencia de restos de cenizas y huesos quemados en el relleno del larnax, algunas puntas de flecha y de lanza sobre el pavimento y un anillo de oro, con el cartucho del faraón Tuthmosis III, que junto con los fragmentos de cerámicas chipriotas (Red-Lustrous Ware) y de importación (Levanto-Heládicas), fechan el santuario en una fase antigua del Chipriota Reciente II, en torno a mediados del siglo $x \vee$ a.C.

\section{LOS SANTUARIOS «URBANOS»}

Los santuarios integrados en los asentamientos son mucho más numerosos que los del grupo anterior y representan, por su frecuencia, una substancial variación frente a lo que es común en las restantes áreas culturales del Egeo, donde, aún cuando los santuarios urbanos no están ausentes, (Myrtos, Mallia, Palaikastro, Pseira, Gournia, Ayia Triadha o Karphy, entre otros, en Creta; Ayia Irini en Keos y Phylakopi en Melos; 
Micenas en Grecia), representan siempre un bajo porcentaje de los lugares de culto conocidos. En Chipre hay varios tipos de "santuarios urbanos", todos ellos bastante peculiares, destacando sobremanera la concentración de edificios de culto que se registra en una zona determinada de Kition, que se utilizaron durante un largo espacio de tiempo, formando un sector del asentamiento destinado únicamente a las actividades cultuales.

2.1.A. Un primer grupo de "santuarios" es el constituido por los que están formados por un único edificio: Maa Palaeokastro (V. Karageorghis, 1980: 761 y ss.; V. Karageorghis, M. Demas, 1981: 135 y ss.; V. Karageorghis et al., 1982: 86 y ss.), Pyla -Kokkinokremos (M. Loulloupis, 1973: 235-36; P. Dikaios, 1971: 896-900) y Palaepaphos (P. Astrom, 1972: 10; F. G. Maier, 1973: 68 y ss.; 1978; 1979: 228 y ss.)-, aunque entre ellos existen diferencias. Los dos primeros recintos se fechan en el siglo XIII a.C., y están situados en asentamientos poderosamente fortificados, en tanto que Palaepaphos es un yacimiento mal conocido todavia, cuyo templo, situado prácticamente bajo el más tardío de Afrodita, por su concepción arquitectónica, es similar a los Templos de Kition, al estar dotado de un amplio "tenemos". De hecho, las diferencias entre estos recintos sagrados son muy notables, sobre todo si atendemos a la planta de los "santuarios" propiamente dichos, ya que tanto en Maa Palaeokastro (fig. 11) como en Pyla Kokkinokremos (fig. 7), los edificios estan ordenados en torno a una habitación o patio central respectivamente, en tanto que en Palaepaphos (fig. 6) la cella se encuentra en una estructura situada en el extremo del amplio temenos.

Respecto a los "santuarios aislados", hay diferencias en las técnicas constructivas, patentes especialmente en la utilización de sillares en los muros, aparejo típico del siglo XIII a.C. en Chipre, aunque el templo de Pyla Kokkinokremos está construido en mampostería simple. Las áreas sagradas están pavimentadas cuidadosamente con arcilla batida, morteros de argamasa y guijarros $y$, en ocasiones, hay una regularización y nivelación de la roca natural, tal como sucede en Pyla Kokkinokremos. Las estructuras rituales son muy numerosas en estos santuarios, destacando la presencia de:

- Bothroi- que aparecieron rellenos de cenizas y materia orgánica quemada, del tipo de los excavados en Maa Palaeokastro (Habitación 19), y especialmente en Pyla Kokkinokremos, donde en el patio (fig. 7 , a-b) se han excavado tres estructuras de este tipo: una situada delante de la stoa, de planta rectangular y $15 \mathrm{~cm}$. de profundidad; otra de unos $85 \mathrm{~cm}$ de profundidad revestida de mampostería, que contenía diversos materiales, entre los que destaca un tripode de bronce. En Palaepaphos, 
los bothroi se encuentran en el interior del edificio, tanto bajo el pavimiento como rompiéndolo, destacando uno de ellos en él que estaba encajado un pithos, quizá destinado a libaciones u ofrendas.

- "Estanques sagrados"- Una de las estructuras excavada en el patio de Pyla Kokkinokremos, de grandes dimensiones y planta rectángular $(1,90$ por $1,30 \mathrm{~m})$, que en su relleno contenía algunas joyas, puede relacionarse con los denominados "estanques sagrados» o piletas, excavados en otros santuarios chipriotas como Kition (Templo 1) y Palaepaphos, donde el "estanque", excavado en la roca, también de planta rectangular, se encuentra situado en el temenos, estando destinado probablemente a la práctica de abluciones.

- Bancos corridos del tipo del localizado en la Habitación 3 de Pyla Kokkinokremos, que no es una estructura construida sino una repisa tallada en la roca, aprovechando una emergencia natural, lo que convierte a este edificio en uno de los "santuarios con banco", tan comunes en el Egeo (G.C. Gessell, 1985), y que pudo ser utilizado tanto como altar como ser un lugar donde disponer los objetos de culto, puesto que encima estaban colocados in situ una moledera y un jarro de cerámica y, caídos a su lado, sobre el pavimento, un pequeño vaso y un pithos. Además, delante del banco se encuentra un gran bothros de planta rectangular en cuyo interior estaban depositados diversos objetos (un hacha de bronce, varias pesas de telar, cerámicas etc..).

En Maa Palaeokastro, los restos de un probable banco corrido de mampostería se localizaron en el interior de la Habitación 25, constituyendo el único dispositivo ritual conocido en el edificio, junto con el bothros y una pileta de piedra pulimentada, hallada en la Habitación 22 (Fig. 11), que también estaba llena de materia orgánica carbonizada.

- Hogares- no son estructurales, sino zonas quemadas, más o menos amplias, que se han localizado en algunas zonas de estos edificios (Habitación 42 de Maa Palaeokastro).

- Altares- aunque no existen estructuras de este tipo en sentido estricto, hay que mencionar la presencia en el temenos de Palaepaphos, delante del "estanque ritual», de un bloque monolítico de piedra, quizá un podium o altar, sobre el que quizá estuvieron colocados originalmente los "Cuernos de la Consagración", también de piedra, hallados en sus proximidades. En el caso de que hubiera sucedido asi, este templo, junto con los de Kition y Myrtou-Pighades, constituirían los más ciaros ejemplos de la importancia que este emblema, de origen minoico, adquirió durante las fases tardías del Bronce Reciente en el Egeo. 
Junto a las estructuras de supuesto carácter ritual se encuentran una serie de objetos "votivos" tales como las figuritas antropomorfas y zoomorfas (bóvidos) halladas en Palaepaphos, el vaso trípode de piedra, localizado en Pyla Kokkinokremos, junto al estanque ritual, que está decorado, en relieve, con unos "Cuernos de la Consagración", poniendo de manifiesto, junto con el ejemplar exento del mismo emblema, localizado en Palaepaphos, la importancia del símbolo en el Chipriota Reciente. La presencia de algunas joyas de oro en los bothros, de vasos y objetos de bronce etc.., pone de relieve contactos con los hallazgos realizados en los yacimientos del grupo anterior, notables especialmente en el caso de Ayios lakovos.

El santuario del Área I de Pyla Kokkinokremos puede fecharse en el Chipriota Reciente IIIA (V. Karageorghis, 1982: 88), en tanto que el de Maa Palaeokastro se fecha en la transición entre el Chipriota Reciente II y el III, para ser abandonado a finales del siglo xIII a.C., tras lo cual, el edificio sería nuevamente reconstruido, aunque ahora su funcionalidad será bien diferente. El templo chipriota situado debajo del Templo de Afrodita en Palaepaphos se ha fechado en el Chipriota Reciente III y, alcontrario que el santuario anteriormente mencionado, continuó siendo una zona destinada al culto, quizá de una deidad femenina $(O$. Masson, 1973: 113), puesto que se conoce no solamente el templo clásico de Afrodita, sino también existen algunas monedas acuñadas en Biblos, en la época del emperador Macrinos, en las que aparece representado un templo local destinado a Astarté, con una representación anicónica de la diosa.

2.1.B. Un segundo grupo de santuarios está formado por complejos que incluyen la cella o santuario propiamente dicho y varios edificios subsidiarios o relacionados directamente con las actividades cultuales. Los dos yacimientos incluidos en este apartado son Idalion (Fases I-III) y Myrtou-Pighades (Niveles 3 y 5), recintos que han sufrido varias reconstrucciones y modificaciones a lo largo de su historia. En ambos, el ordenamiento del espacio es, en cierta forma, similar, ya que cuentan con grandes patios, en torno a los cuales se disponen las diferentes construcciones que forman el complejo, con una disposición similar a la conocida en Ayia Irini, uno de los "santuarios aislados".

Myrtou-Pighades, al Norte de la isla, e Idalion, en el centro (fig. 11) representan dos de los más importantes complejos religiosos chipriotas, tanto por su arquitectura como por su secuencia estratigráfica, que evidencia una utilización continua, durante bastante tiempo, de los recintos como áreas de culto. 
- Idalion (P. Astrom, 1972: 4-5; E. Gjerstad et Al., 1934, 505 y ss.; O. Masson, 1973: 110), situado en Ambelleri, es un asentamiento que cuenta con un poderoso recinto fortificado, junto al cual se encuentra el santuario, que se inicia en la denominada Fase I (Chipriota Reciente III A), momento en el que consta únicamente de dos habitaciones (fig. 3, 33 y 34 ) de planta aproximadamente trapezoidal, en una de las cuales había un altar o "mesa de ofrendas» de mampostería y planta cuadrada, delante del cual estaban depositadas las ofrendas. Delante del edificio hay un patio abierto bordeado por habitaciones en el lado NW y un muro de cierre en el $\mathrm{S}$, en tanto que al SW habia varias estructuras en las que aparecieron vasos de almacenamiento. En el patio o espacio abierto se encontró un bothros de planta circular, excavado en la roca, que apareció relleno de materia orgánica carbonizada y restos de otras ofrendas.

Durante la Fase II, el "santuario" construido en la fase anterior con muros de zócalos de mampostería y alzados de adobe, se mantiene prácticamente intacto, ya que las modificaciones afectan sobre todo a los edificios del borde NW del patio, que se abandonan, nivelándose los derrumbes, ampliando el espacio ocupado por el patio. Las funciones de estas dependencias serán desempeñadas ahora por la llamada Casa Norte. Al SW del edificio se encuentran dos estancias (fig. 4, 38-39), los antiguos almacenes, que apenas sutren alteraciones. Los pavimentos, que, en la Fase I estaban limitados a una mezcla de tierra y guijarros que rellenaba las oquedades de la roca natural, durante la Fase II están hechos con capas de arcilla compacta, mezclada con guijarros.

Un importante nivel de destrucción marca el final de la Fase II (Chipriota Reciente III B) del asentamiento, destrucción que afectó profundamente al Santuario, hasta el punto que fue necesario reconstruir algunos de sus muros, situación que se aprovechó para añadir una nueva estancia al conjunto (fig. 5, 36). La puerta que anteriormente comunicaba las dos habitaciones originales fue cerrada, pero se abrió una nueva situada a escasa distancia $(50 \mathrm{~cm})$ hacia el NE. El altar también fue substituido a finales de la Fase III (Chipriota Reciente III C) por uno de planta rectangular y grandes dimensiones $(1,80$ por $1 \mathrm{~m}$.), igualmente construido con mampostería (fig. 5,34 ). Los almacenes del sector SW fueron modificados y es probable que las habitaciones 35 y 36 (fig. 5) fueran los almacenes del santuario, unos «repositorios" semejantes a los conocidos en otros lugares del Egeo, ya que en su interior estaba depositada una importante colección de objetos, entre los que destacan cilindros-sello, cuentas de fayenza, agujas etc..., similares a los encontrados en el interior de la cella del santuario. 


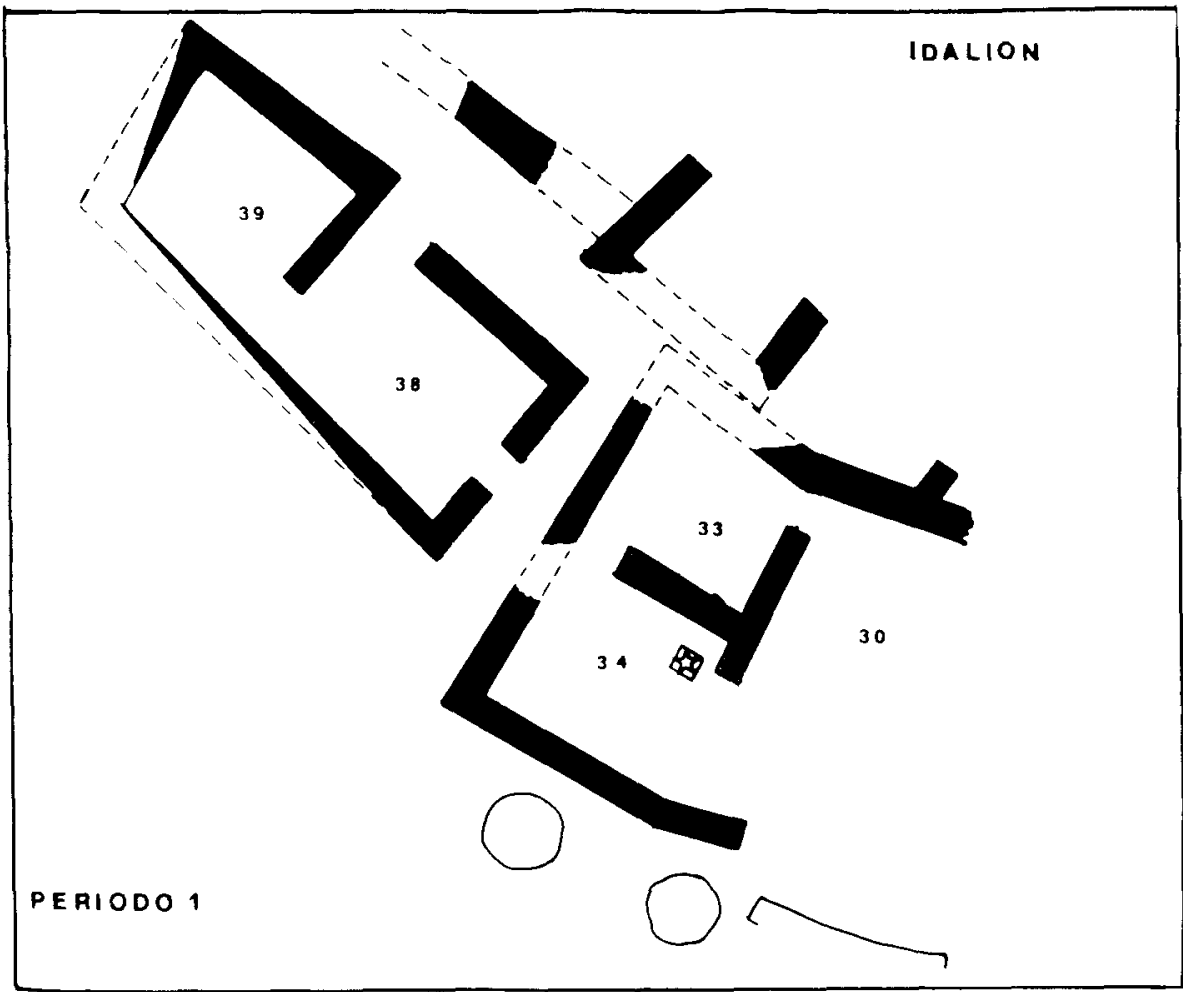

Fig. 3.

El santuario carece de otras estructuras rituales que no sean los altares y los diferentes bothroi excavados en el patio, faltando los hogares, mesas de ofrendas (fijas o portátiles) o bancos corridos conocidos en otros lugares, sin embargo, su función ritual parece estar evidenciada por el hallazgo en la cella (figs. $3-5,34$ ) de una serie de objetos de culto depositados en torno al altar: vasos de libación, figurillas de bóvidos, sellos cilíndricos, agujas y anillos de bronce y oro etc. (C. G. Yavis, 1949: 49).

- Myrtou-Pighades, un asentamiento del Norte de la isla, cuenta con una zona destinada a cultos desde el Chipriota Reciente II A2 (P. Astrom, 1972: 5-9), que se corresponde con la Fase o Periodo III del yacimiento (J. Du Plat Taylor et Al., 1957). Los restos conservados de esta época son muy limitados, pero ya se aprecia el trazado general que tuvo el complejo. Un patio o espacio abierto (fig. 8,3) de planta rectan- 


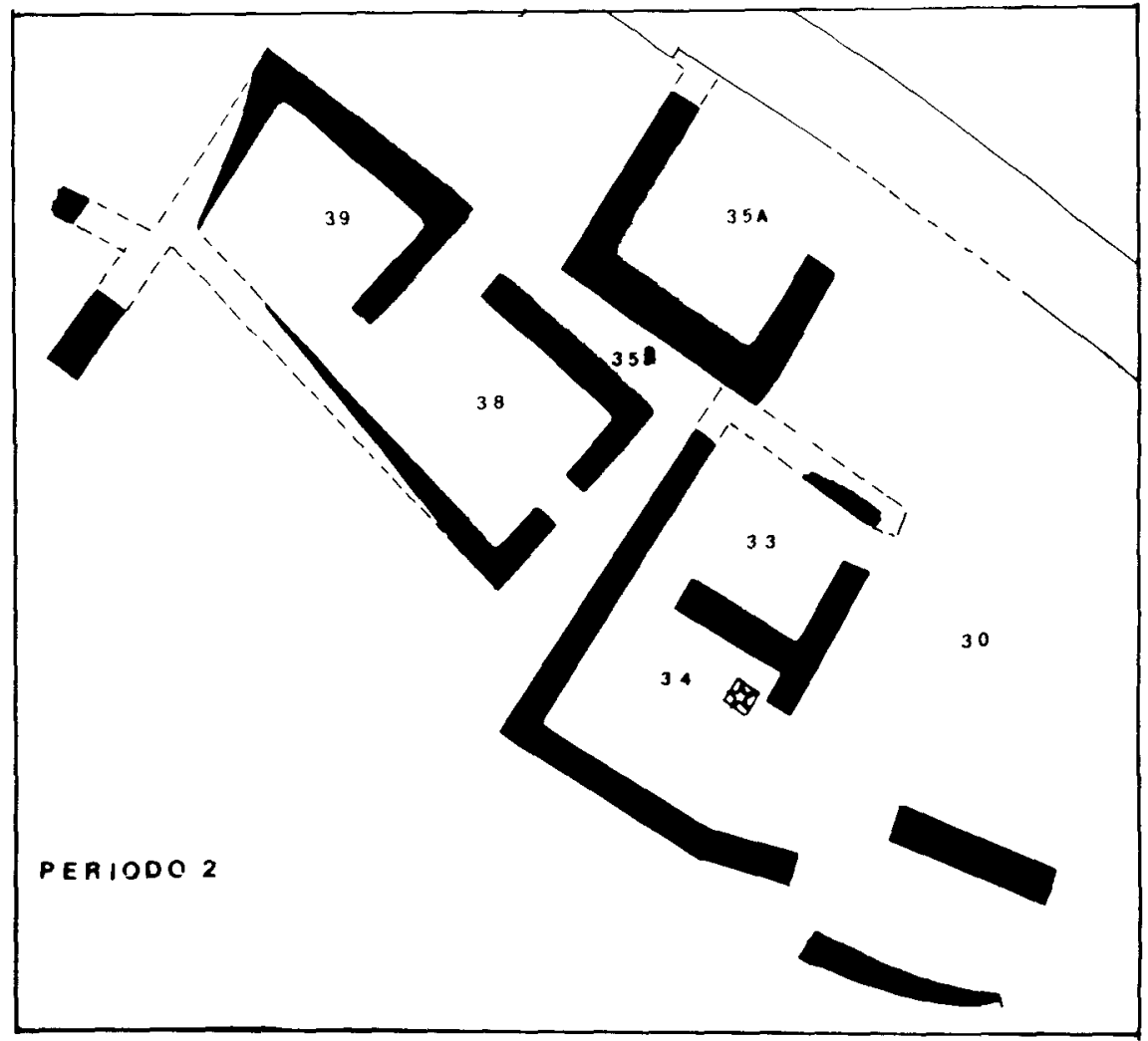

Fig. 4.

gular, al que se accedía a través de una estancia situada al Oeste (fig. $10,2)$, que está limitado al Norte por un muro y al Este por otro, dejando un estrecho pasaje de acceso en el ángulo NE. Al Sur del patio se extienden una serie de habitaciones de funcionalidad no bien conocida.

Los muros del complejo están construidos con zócalos de mamposteria y alzados de adobe, las puertas están dotadas de umbrales de piedra y los pavimentos están hechos con lajas de gypsum o con tierra batida. Las estructuras rituales son bastante limitadas, ya que tan sólo se ha localizado un gran bothros excavado en la roca, de planta aproximadamente circular, en la Habitación 2, donde existia otro "pozo" de dimensiones más reducidas, pero destaca la presencia de un podium o plataforma de mampostería en el patio, dispuesto directamente sobre la 


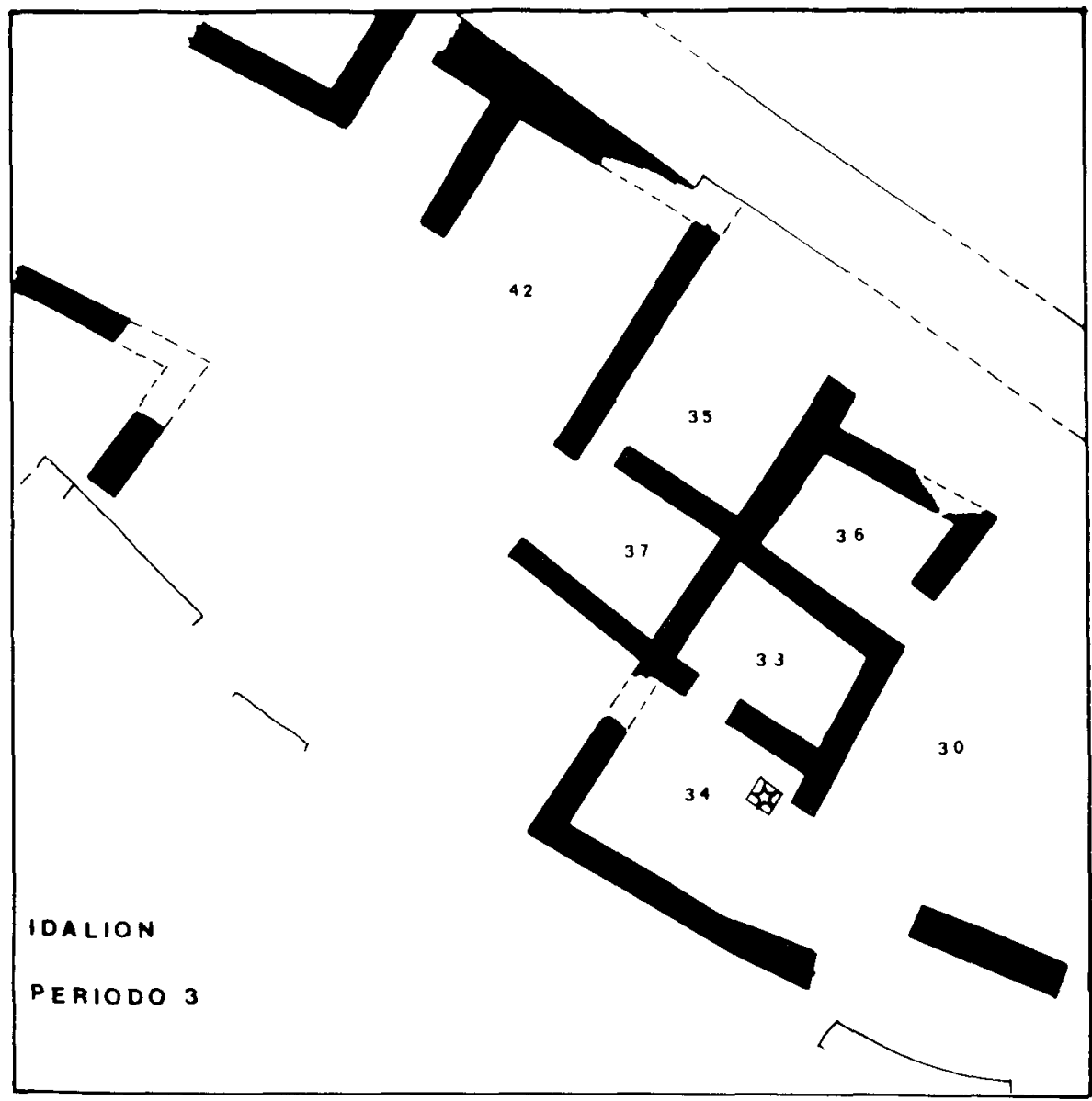

Fig. 5.

roca natural, al cual debia accederse por una especie de rampa desde la puerta de la Habitación 2.

Los objetos votivos son muy numerosos, destacando la presencia de varias figurillas de toros de arcilla, algunas pintadas, una figurilla antropomorfa y una cornamenta de carnero cuidadosamente depositada sobre el pavimento de una de las habitaciones del lado Sur del complejo. Los materiales cerámicos, especialmente cerámicas chipriotas pintadas de estilo White Slip III, cuencos de tipo Base-ring, cerámicas monócromas rojas de tipo Apliki etc..., sitúan la utilización de este santuario durante el Chipriota Reciente IIA ( $\pm 1400-1300$ a.C.). 


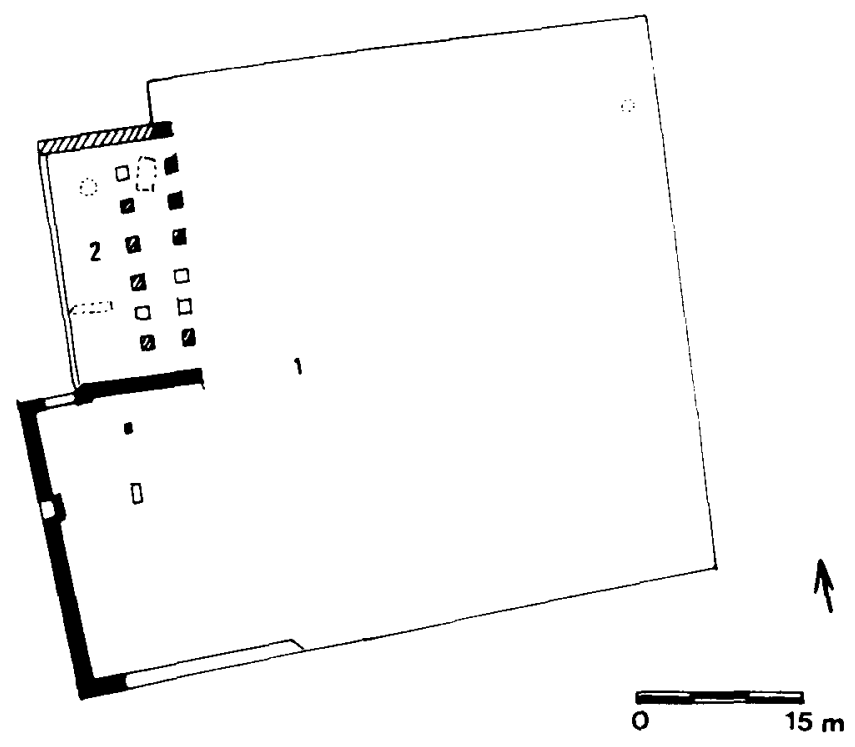

PALAEPAPHOS

Fig. 6.

Más tarde, durante la Fase o Período $V$, tras una destrucción en el yacimiento, el santuario fue substancialmente remodelado, ampliando el espacio que ocupaba y añadiendo numerosas estructuras subsidiarias. Durante esta fase, que se inicia a principios del siglo xIII a.C., y que se fecha por la presencia de un anillo con el cartucho del faraón Ramses II (1301-1236 a.C.) y parece finalizar casi unos 150 años más tarde, tal como indican las cerámicas micénicas de tipo $\mathrm{HR}$ III C1, el complejo adquirió una enorme importancia, incorporando, al igual que Palaepaphos y Kition, uno de los emblemas más significativos del ámbito religiosopolítico del Egeo, los "Cuernos de la Consagración", que coronaban un altar monumental, situado en el centro del patio del santuario.

El complejo está constituido por el "santuario" con varias dependencias y una serie de edificios anejos, en los que también se desarrollaban actividades rituales o estaban destinados a servicios (fig. 9). Los muros están construidos con zócalos de mampostería, sobre los que se dispuso una capa de mortero, encima de la cual el alzado era de adobe o de tapial rojo. Apenas existen puertas, que están dotadas de umbrales de lajas de piedra, y los pavimentos son de arcilla batida, aunque en el patio existen algunas zonas empedradas con guijarros y en varias habitaciones 


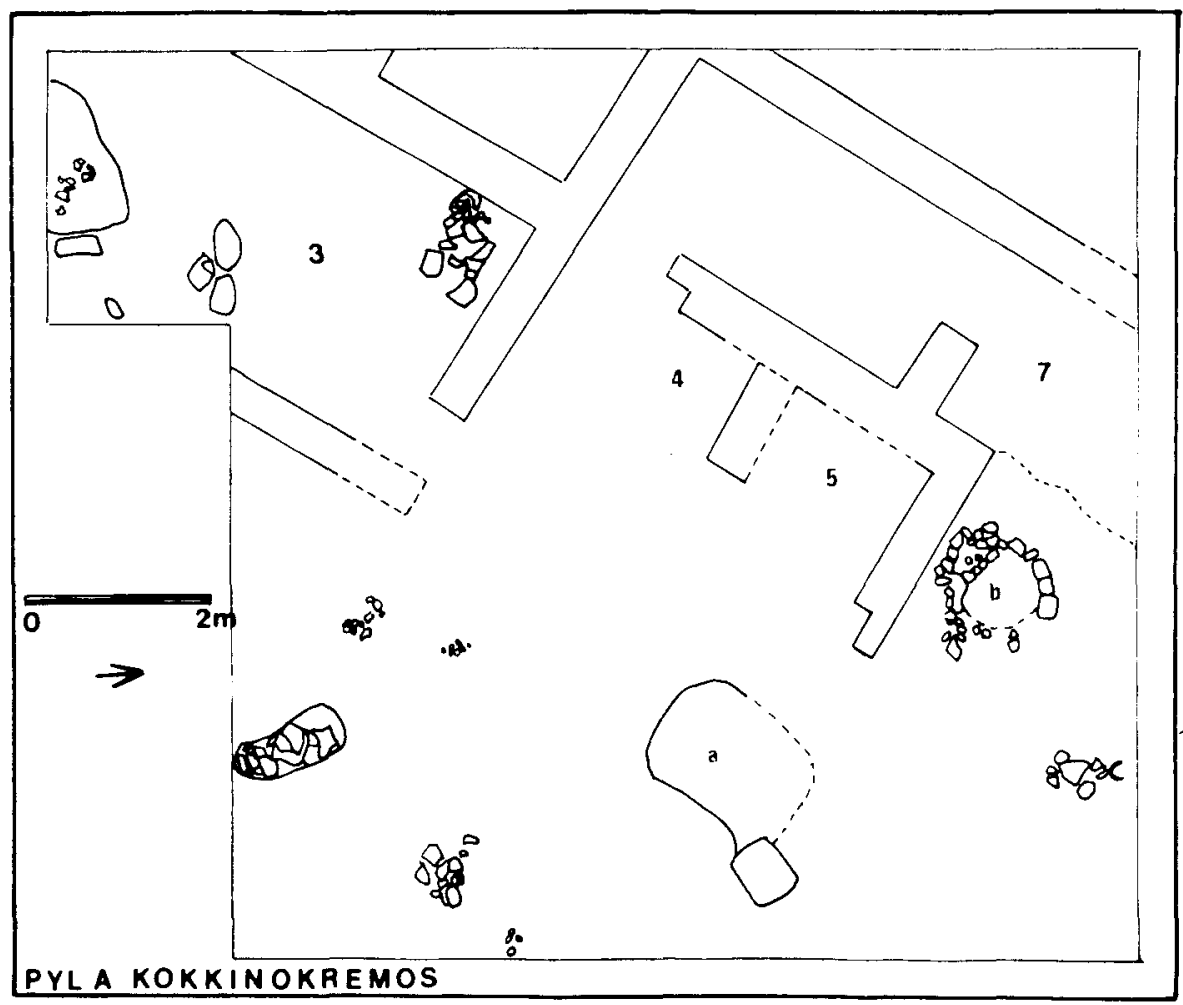

Fig. 7.

hay pavimentos de lajas de gypsum. Quizá lo más significativo es la ausencia de sillares en la construcción del edificio, ya que durante las últimas fases del Bronce Reciente el empleo de este material constructivo se convirtió en habitual en los grandes asentamientos, tal como sucede en Enkomi o Kition.

El patio está limitado al Norte por un muro, y por el Este por el muro occidental del denominado "Bloque Este», que tiene adosado en toda su longitud un banco corrido de mampostería (fig. 9) de unos $45 \mathrm{~cm}$ de altura en cuya cara superior se conservaban varias piedras perforadas intencionadamente que, según los excavadores, estuvieron destinadas a trabar los animales, posiblemente toros, que se sacrificaban en las ceremonias religiosas, opinión compartida por V. Karageorghis (1982: 69). En los lados Este y Sur del patio se encuentran una serie de habitaciones (fig. 9, 1-7) subsidiarias. El acceso al santuario se realizaba, como en el 


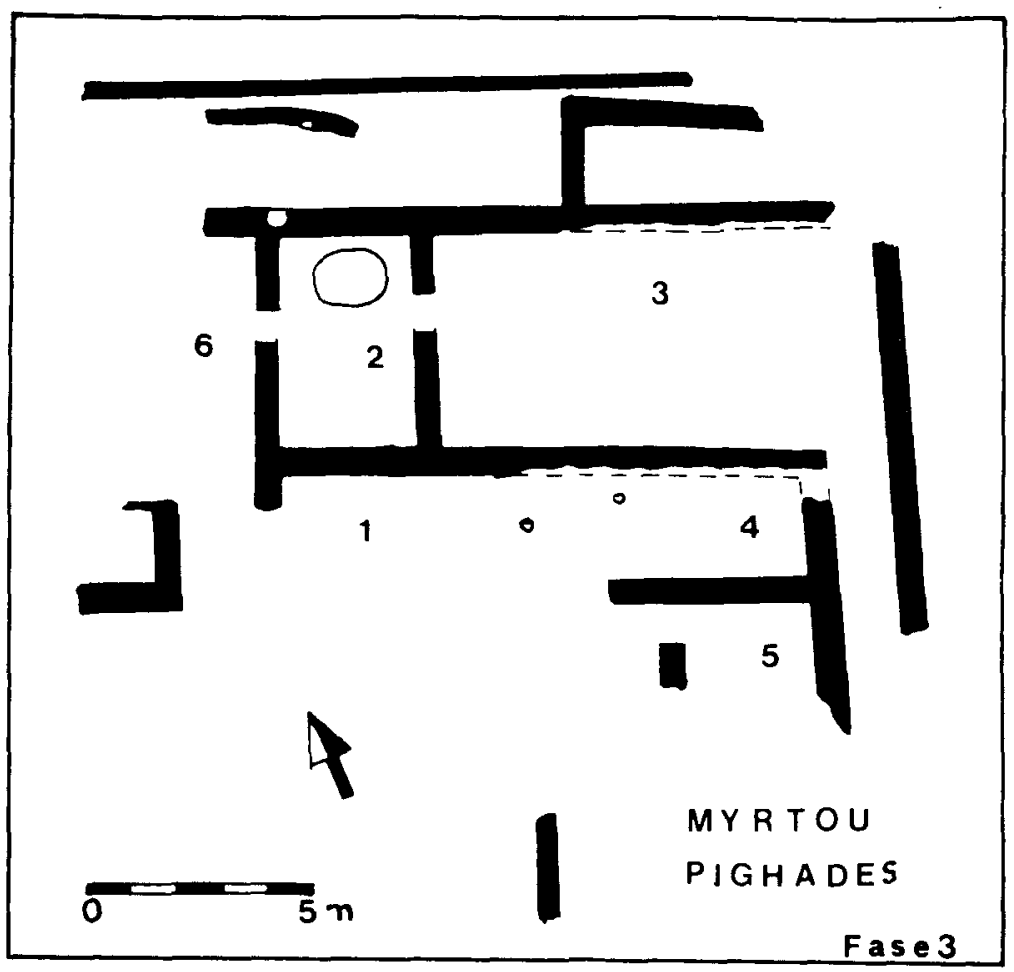

Fig. 8.

edificio más antiguo, por el ángulo NE del patio, donde se abre una calle que corre en dirección E-W, cerrada al Norte por un muro alineado con el que cierra el recinto sagrado y que en los muros Este y Norte del "Bloque Este", está dotado de un banco corrido de mamposteria en toda su longitud.

El "Bloque Este" (fig. 9, 8-24) es un conjunto de habitaciones ordenadas en torno a un patio central (fig. 9, 12), en una de las cuales había un banco corrido (fig. 9, 16) y en otra, la única que tiene un acceso directo desde la calle, una mesa de ofrendas de piedra (fig. 9,8). En el extremo Sur del edificio se encuentra una sala pavimentada con lajas que fue interpretada como un posible adyton o Sala Lustral, dispositivo que complementaria las estructuras rituales del complejo, estructuras que, por otra parte, son bastante limitadas.

En efecto, en el complejo del Santuario de Myrtou las estructuras rituales se concentran casi exclusivamente en el patio, donde está si- 


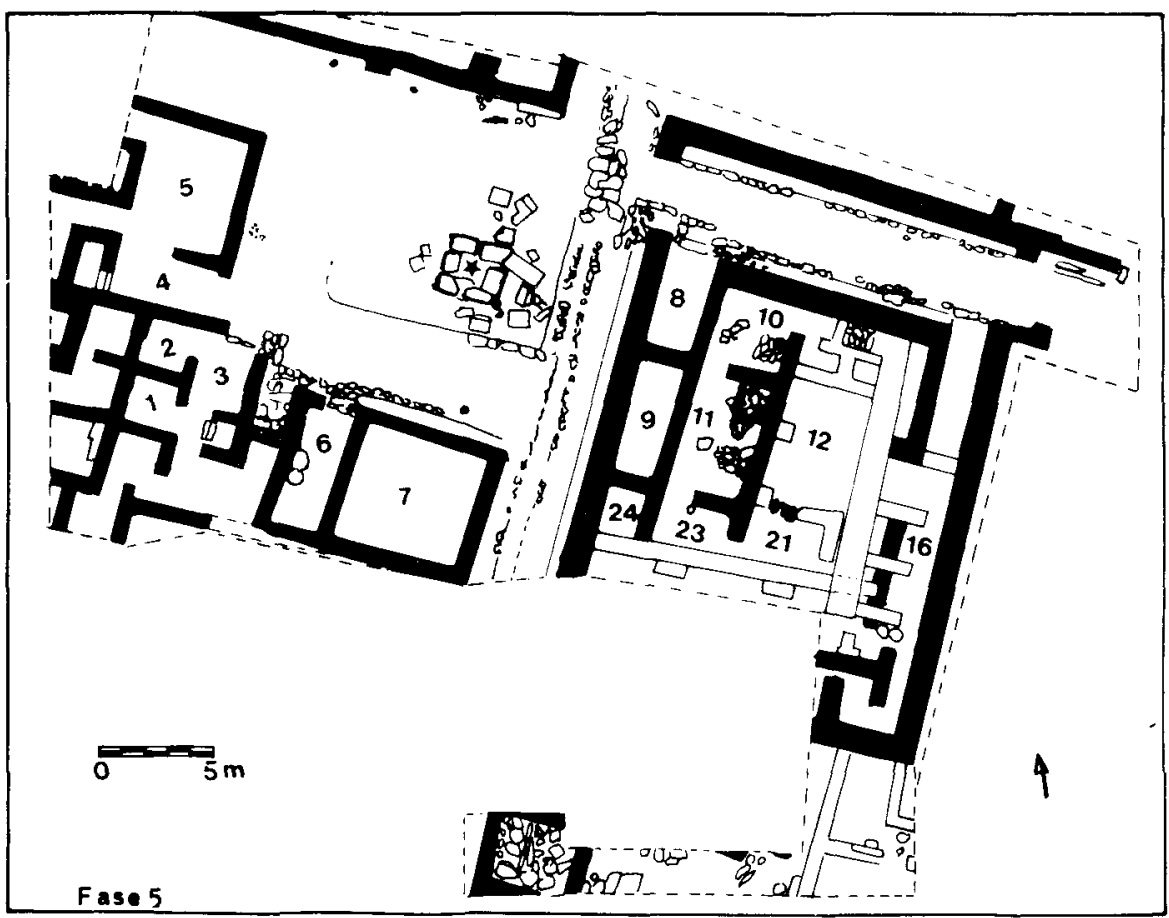

Fig. 9.

tuado un gran altar escalonado, bajo el cual se han localizado los restos de otra estructura similar, de planta casi rectangular $(2,30$ por 2,20 m) del que se conservaban tan sólo unos $50 \mathrm{~cm}$ de altura (V. Karageorghis, 1970: 299). El altar conservado es de planta cuadrada, con $2,50 \mathrm{~m}$ de lado, y debió alcanzar unos $5 \mathrm{~m}$ de altura. Tiene cinco escalones hechos con grandes sillares, que se disponen formando cuadrados que disminuyen progresivamente sus dimensiones. En la hilada superior se integran dos bloques tallados en forma de "Cuernos de la Consagración», de tamaño monumental, que confieren carácter sagrado al recinto.

En la base del altar escalonado, en cada uno de los ángulos, se encuentran unas piedras perforadas que pudieron ser utilizadas para soportar estandartes, al estilo de lo que se hacía en los templos egipcios contemporáneos, o bien en las que se colocaban postes para sostener los bucrania, aunque M. Loulloupis (1973: 227-231) sugiere que estaban destinados a libaciones. Una peculiaridad de este altar es que sus án- 


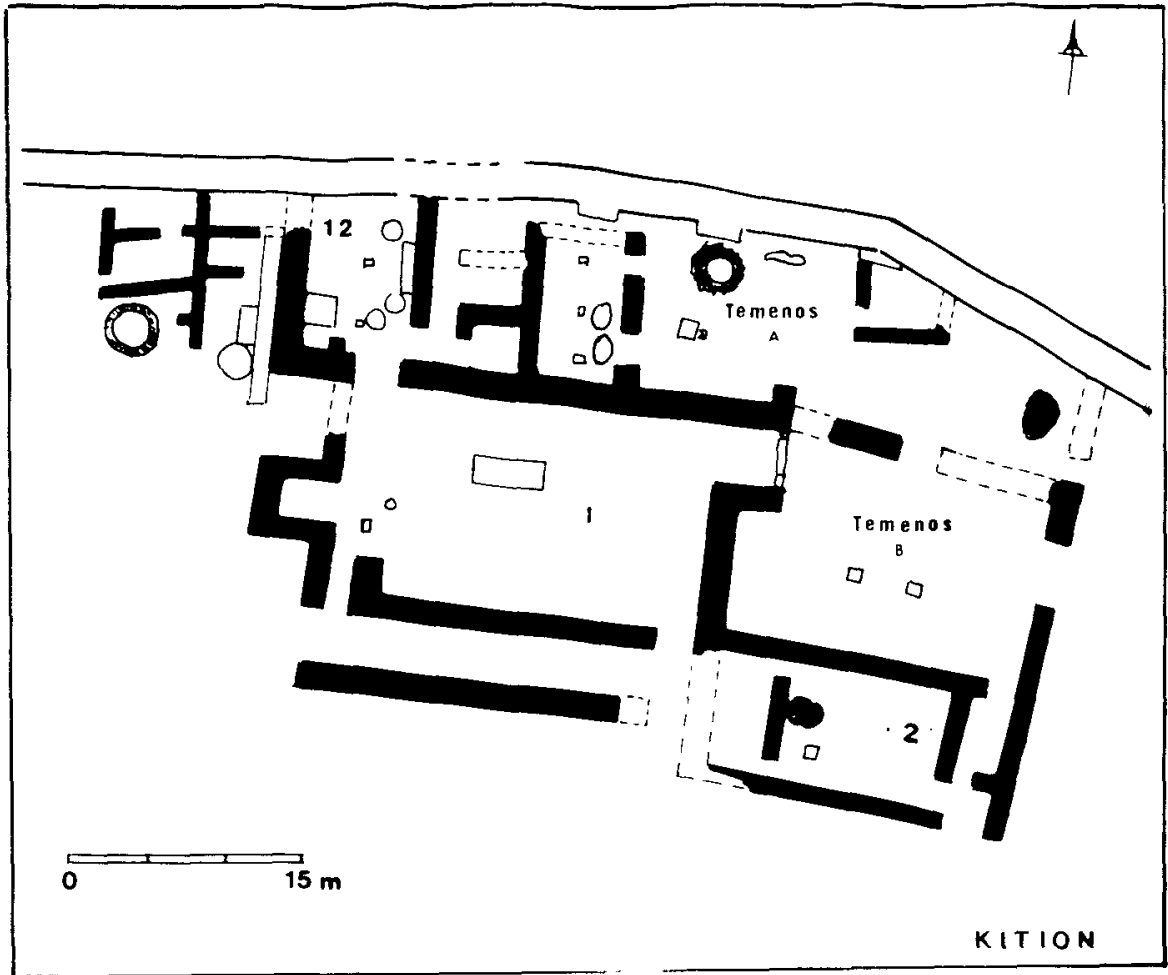

Fig. 10.

gulos están orientados hacia los cuatro puntos cardinales, por lo que también se ha sugerido la posibilidad de que parte de los ritos estuvieran vinculados a cultos astrales o quizá, simplemente, relacionados con actividades de observación astronómica.

Al Norte del altar, una gran laja de piedra, parcialmente incrustada en el pavimiento, lleva también una perforación, lo que ha hecho suponer que quizá se trataba de una mesa de ofrendas en la que se practicaban libaciones $u$ ofrendas líquidas, semejantes a las celebradas al pie del altar escalonado, ya que en su lado Este se encuentra una atarjea o canal de desagüe que enlaza con el canal principal que discurre bajo el pavimiento de la calle. Algunas de las zonas empedradas del patio mostraban evidencias de fuego, tratándose posiblemente de hogares no estructurales, en los que se quemaban algunas ofrendas. 


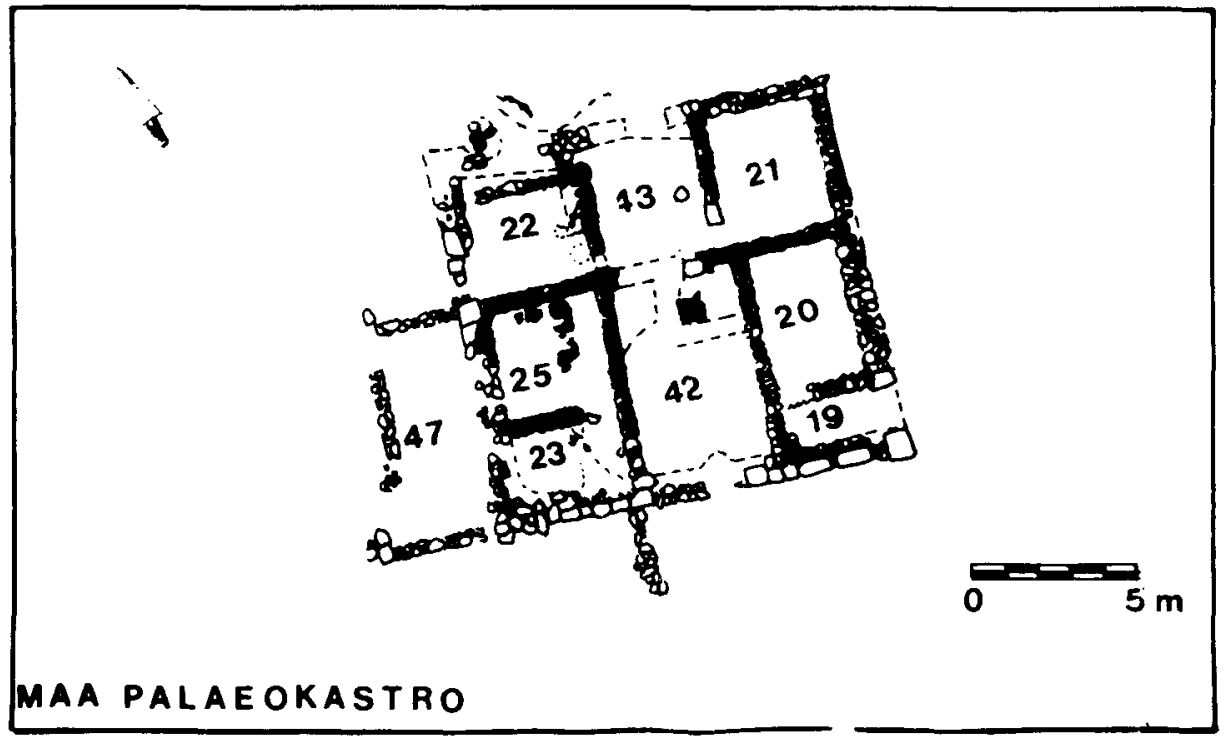

Fig. 11.

Así pues, los dispositivos o estructuras rituales son escasos: hogares no estructurales, mesas de ofrendas, bancos corridos y, especialmente, el monumental altar escalonado, estructura que no tiene paralelos en ningún otro santuario chipriota ni del Egeo, aunque podría ponerse en relación con altares-plataforma cretenses, del tipo de los conocidos en el Patio Occidental de Knossos y en Nirou-Khani (B. Rutkowski, 1986: 120). Los objetos votivos son más numerosos, pero no se encontraron en torno al altar sino dispersos por el complejo. Entre estos objetos destaca la presencia de un rhyton micénico, dobles-hachas, jarros de libación, un altar de paredes incurvadas, fragmentado, un torito de bronce y otro de arcilla, un sello cilíndrico y una mesa de ofrendas "tripode", hallada en la Habitación 15 del Bloque Este.

Una gran importancia tiene el hallazgo, en las proximidades del altar, de un amontonamiento de cornamentas y huesos de animales, entre los que hay bóvidos, ciervos, cabra, muflón y ovejas, que supuestamente deben proceder de las ofrendas, y quizá sacrificios rituales, ejecutados en los últimos momentos de utilización del santuario. Las cornamentas o huesos de animales son comunes en otros santuarios chipriotas, siendo especialmente notable la importancia que este tipo de depósitos tiene en los santuarios urbano-domésticos de Enkomi y en el Templo 5 de Kition. 
2.2. Las "Áreas de Culto", es decir, zonas de los asentamientos en las que se concentran varios recintos destinados a actividades rituales, están representadas en Chipre por el conjunto de templos de Kition, situados en el Área II (G. Clerc et Al., 1976, 1), construidos en momentos diferentes y que sufrieron modificaciones en el transcurso de su historia. No obstante, los cinco templos excavados, situados en las proximidades de la muralla y cerca de una de las puertas de la misma, en una posición similar a la ocupada por el Santuario de Idalión, tienen algunas características comunes como indican sus plantas, que son muy semejantes, tanto en el caso de los fechados en el Chipriota Reciente II (Templos 2 y 3) como en los datados en el Chipriota Reciente III (Templos 1, 4 y 5): rectangulares, constan de un patio y una cella (figs. 10,12,13) que se sitúa en el extremo Oeste del mismo, salvo en el Templo 4, donde la cella está situada en el Este. La mayor parte de las cellae está sin compartimentar, aunque en los Templos 1 y 4 hay muros de división interna que dan lugar a varios habitáculos.

Los dos templos más antiguos (2 y 3) están construidos con mampostería de aparejo irregular y alzados de adobe, tienen pavimientos de arcilla batida y de lajas en algunas zonas. Las estructuras rituales están

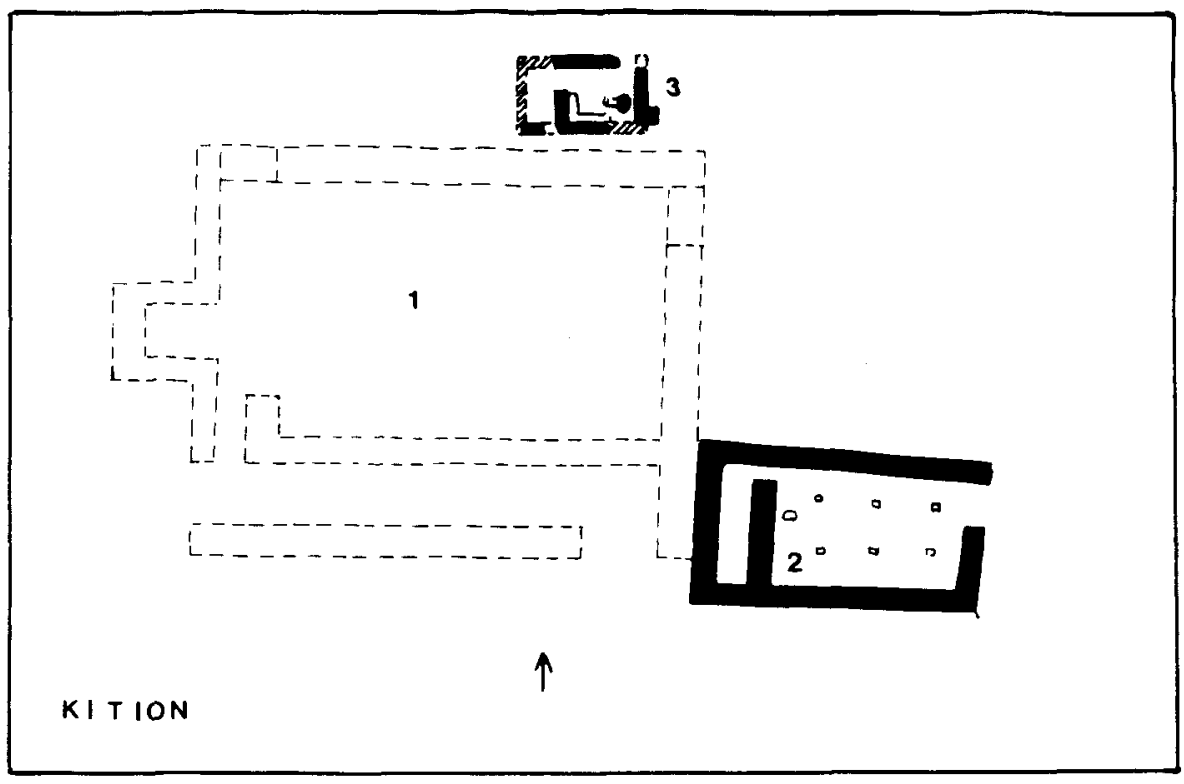

Fig. 12. 


\section{Templo 2}

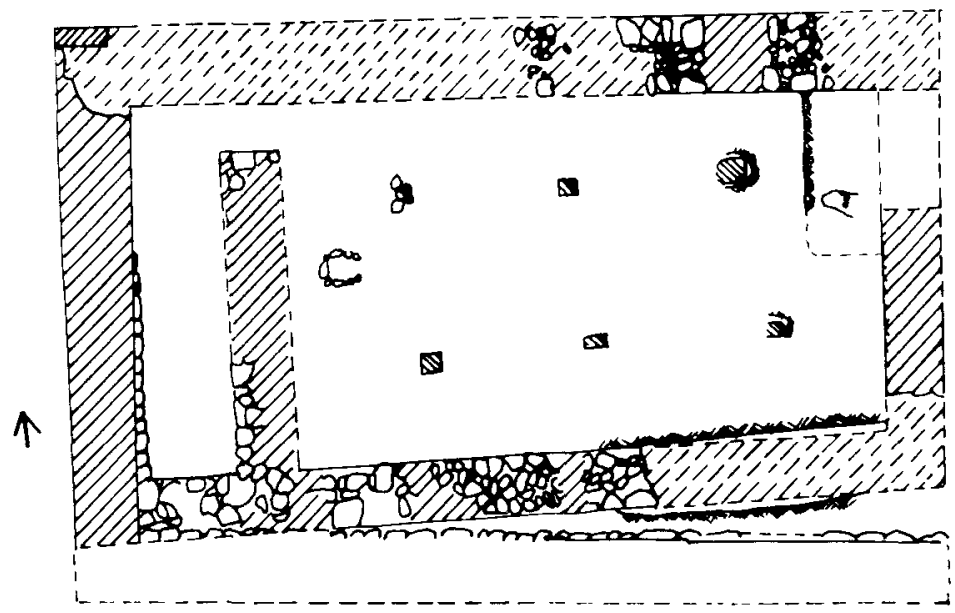

Fig. 13.

situadas en los patios, en uno de los cuales puede suponerse la existencia de un pórtico o stoa (Templo 2), y comprenden:

- un altar o quizá un "hogar ritual», de mampostería y planta cuadrada $(1,30 \mathrm{~m}$ de lado) que apareció relleno de cenizas y huesos de animales quemados, situado en el patio del Templo 2, delante de la cella.

- un altar-hogar, semejante al anterior y una mesa de ofrendas, también de mampostería, delante del mismo, que forman un conjunto de $1,54 \mathrm{~m}$ por $1,00 \mathrm{~m}$, situado delante de la cella del Templo 3 .

- en el Templo 3, un banco corrido de mampostería, situado a lo largo del muro Sur y del muro divisorio de la cella, que quizá fue utilizado para depositar las ofrendas y objetos de culto.

Desde la fase más antigua de estos templos parece existir una vinculación directa entre los recintos sagrados y los talleres de fundidores situados al Oeste del Templo 3 y al Norte del posterior Templo 1, por lo que $V$. Karageorghis (1970: 338 y nota 87 ) ha sugerido la posibilidad de que en los templos se hubieran adorado dos deidades - una femenina y 
otra masculina- quizá el "dios y la diosa" de la metalurgia chipriotas, que podian ponerse en relación con las deidades adoradas en los Templos de Enkomi, asi como con algunos dioses próximo-orientales, especialmente los adorados en Beisan. Desde otro punto de vista, la vinculación entre las actividades metalúrgicas y los templos, puede interpretarse como una de las funciones económicas de estas instituciones, función que probablemente desarrollaron también los santuarios fenicios (A. Vázquez y C. Poyato: en prensa).

Una de las instalaciones más peculiares del Área de Culto de Kition, es el llamado "Jardín Sagrado", situado entre los Templos 2 y 3, cerrado por un muro de mampostería, en el que se han excavado numerosas fosas o bothroi, algunas de las cuales aparecieron rellenas de cerámicas, cenizas y materia orgánica quemada, en tanto que otras han sido interpretadas como las fosas de los árboles sagrados (V. Karageorghis, 1980: 761). Este “jardín» desapareció en la fase siguiente, ya que el espacio fue ocupado por la construcción del Templo 1.

Los templos del Chipriota Reciente III $(1,4,5$ y reconstrucción del Templo 2) mantienen una disposición general semejante a la que tenian los más antiguos, aunque ahora se integran en un conjunto en el que la distribución general tiene un aire de monumentalidad que le viene dado por el empleo de sillares en los muros de los diferentes recintos sagrados, templos y témenoi, así como en las entradas o puertas monumentales que aparecen en el recinto, especialmente en el sector oriental, ya que los Templos 4 y 5 continúan la tradición anterior, al estar construidos sus muros con mampostería sencilla, aunque dado el mal estado de conservación en que se encontraban no puede descartarse que los zócalos conservados fueran el plinto o basamento de varias hiladas de sillares (V. Karageorghis, 1976: 78).

La mayor novedad la supone la aparición de los Témenoi A y B (fig. 10) vinculados a los Templos 1 y 2 , y que ocupan el espacio delimitado por ellos y la muralla. Tienen plantas irregulares, pero constituyen unos espacios abiertos en los que debian desarrollarse ceremonias públicas, ya que conforman los accesos directos desde la calle a los Templos 1 y 2. El Templo 1 se construyó a finales del siglo XIII a.C. sobre los restos del Templo 3 y el «jardín sagrado", con un gran patio y una cella tripartita en el lado Oeste; su entrada principal, al Este, cuenta con una especie de propileo en el que dos perforaciones en las lajas de piedra pudieron servir para colocar estandartes. El Templo 2 fue remodelado, desapareciendo la stoa (V. Karageorghis, 1971:384-85), al tiempo que se disponía un nuevo pavimento y se colocaba junto al antiguo altar una nueva "mesa de ofrendas" de grandes dimensiones $(1,10$ por $0,90 \mathrm{~m}$ y $35 \mathrm{~cm}$ 
de altura) construida, igualmente, de mampostería (V. Karageorghis, 1982: 94). Este edificio continuó estando en uso hasta finales del siglo XI a.C., como el Templo 1, con la particularidad de que cuando se levantó el Templo de Astarté, a finales del Ix a.C., el área ocupada por el Templo 2 todavía continuaba utilizándose como Témenos, es decir, como un recinto sagrado.

Las estructuras rituales de los templos continúan siendo escasas, pero, además de la "mesa de ofrendas" y el altar del Templo 2, destaca la estructura localizada aproximadamente en el centro del Templo 1, el llamado "estanque sagrado" - una fosa excavada en la roca de planta rectangular $(4,60$ por $1,80 \mathrm{~m}$.) y una profundidad de casi $90 \mathrm{~cm}$-que puede ponerse en relación con los "lagos sagrados" comunes en los templos egipcios de época de las Dinastias XVIII y XIX (V. Karageorghis, 1982: 94), además un pequeño bothros situado delante de la cella, completa los dispositivos del Templo 1 (V. Karageorghis, 1971: 379).

Los témenoi $\mathrm{A}$ y $\mathrm{B}$ estaban provistos de estructuras rituales muy especiales ya que en ambos se han localizado dos altares (?) construidos con mampostería sobre los que estuvieron colocados sendos pares de "Cuernos de la Consagración" (V. Karageorghis, 1976: 69-72). En el Témenos A (Fig. 10), el altar es de planta cuadrada (1,20 m de lado) y se conservaba hasta una altura de $60 \mathrm{c}$, junto a él, estaban caídos el par de "Cuernos de la Consagración" tallados en un bloque de caliza local (M. Loulloupis, 1973: 226-227), que quizá, como en Myrtou-Pighades, coronaban la estructura, confiriendo carácter sagrado al recinto. Cerca de este altar se encuentra otra estructura, de planta aproximadamente oval y diámetro máximo de $1,50 \mathrm{~m}$ que apareció cubierta de cenizas, huesos quemados y fragmentos de cerámicas, que también cubrian sus inmediaciones, por lo que se ha interpretado como un lugar donde se celebraban las ofrendas. Una zona cubierta de cenizas apareció en el extremo Este del témenos y aunque no habia restos de estructuras, podria interpretarse también como un "hogar ritual no estructural"; entre los materiales recogidos en el recinto destaca la presencia de escorias de fundición de cobre en niveles que contenían cerámicas de tipo HR IIIB.

En el Témenos $B$ se conservaban dos basas para columnas que, junto con dos capiteles hallados en la zona, quizá sostenían un pórtico 0 stoa, elemento arquitectónico tradicional y bastante común en los templos chripriotas. Además se encontró un par de "Cuernos de la Consagración" tallados en dos bloques de caliza, y aunque no habia restos de ningún altar, es probable que este emblema haya ocupado en el témenos $\mathrm{B}$, una posición semejante a la que tenía en el témenos A. Así pues, en Chipre, serían al menos cuatro los templos en los que habría "Cuernos 
de la Consagración" coronando altares de diferentes tipos, lo que constituye un caso único en el Mediterráneo Oriental, ya que ni tan siquiera en Creta se conocen tantas estructuras de este tipo.

Tras una destrucción que parece tener lugar en la época de los Pueblos del Mar, los témenoi fueron remodelados. En el témenos A, desapareció el altar oval, pero el que soportaba los "Cuernos de la Consagración" continuó utilizándose, y en el témenos B se levantó un altar de planta cuadrada en el ángulo NE, en torno al cual había cenizas y huesos quemados.

Al otro lado de la calle y de un espacio abierto, se encuentran los Templos 4 y 5 que carecen de témenos, pero que ofrecen, en cambio algunas estructuras y una disposición general de gran interés. Están separados uno de otro por una estrecha calle y ambos fueron construidos durante el Chipriota Reciente III. El Templo 4, de planta rectangular tiene una doble cella en el lado oriental del patio, está apoyado en la muralla por su lado Norte y tiene un banco corrido precisamente adosado a ese muro. La presencia de varias basas para columnas hacen suponer que tenía una stoa en el lado Norte, en tanto que otras dos basas, una de ellas con una perforación, quizá para sostener un poste de madera - no estructural- que $V$. Karageorghis ha puesto en relación con las deidades adoradas en los santuarios cananeos (Asherah), a su vez vinculadas al "Árbol de la Vida" (1976: 79).

Las estructuras rituales son bastantes escasas, destacando un pozo o bothros en el extremo occidental del patio que contenía fragmentos de cerámica micénicas del tipo IIIC 1b, y de grandes pithoi de almacenamiento. No existen evidencias de hogares estructurales, pero junto a las entradas del templo se encontraron dos pilas de huesos de animales quemados mezclados con fragmentos cerámicos.

Los objetos votivos se limitan a un conjunto de cerámicas, en su mayor parte jarros y otros vasos de libación de tipo Base-ring, un anillo de oro grabado con un toro y un mango de objeto de marfil, depositados sobre los pavimentos de la cella doble. La pieza de marfil ha sido identificada como parte de una "pipa" utilizada para fumar opio, que quizá se consumia en las prácticas rituales o con fines medicinales (V. Karageorghis, 1982, 105). Pero quizá el hallazgo más significativo es un depósito, quizá fundacional, formado por dos útiles agricolas y un "clavo" de bronce, que estaban depositados, bajo el pavimento III, en el ángulo NW del pario. Los "clavos" aparecen con frecuencia en los depósitos fundacionales del Próximo Oriente y Mesopotamia, y generalmente se encuentran en posición vertical, aunque el objeto de Kition estaba horizontal, 
pero en todo caso revela, junto con la probable Asherah, la influencia de los cultos y creencias próximo -orientales en Chipre, aunque en Kition, parecen integrarse estos cultos con los de origen Egeo en la misma Área de Cultos.

El Templo 5 tiene la cella en el lado Oeste - un estrecho compartimiento de entrada lateral- El patio es rectangular y está dotado de los bancos corridos, uno adosado al muro Sur y otro al Norte. La única estructura ritual es una mesa de ofrendas, de planta rectangular (2 por $1,80 \mathrm{~m}$ ) situada en el lado Oeste del patio, pero destaca la presencia de algunas zonas quemadas, cubiertas de cenizas y huesos quemados, que bien pueden ser "hogares rituales no estructurales", asi como los abundantes restos de cráneos y cornamentas de bóvidos, ciervos y otros animales con cuernos, hallados en todo el patio, sugieren que se hacian sacrificios en este templo. Además, la presencia de un "ancla» de piedra, apoyada contra el muro de la cella, y de varios barcos grabados en los muros del edificio 1 , hacen sospechar que quizá estaba dedicado a una deidad marina, protectora de los navegantes, a las que debian ofrendarse los animales.

Frente a lo que sucede en otros santuarios chipriotas, en Kition faltan las figurillas de bóvidos y antropomorfas, lo que es compensado por la riqueza de las estructuras rituales, la presencia de restos de animales sacrificados y la importancia que tiene los emblemas sagrados, los "Cuernos de la Consagración". Asímismo, en este yacimiento existe una relación directa entre los recintos sagrados y los "talleres de fundidores" excavados en el extremo occidental del Área de Culto a lo largo de toda la secuencia (V. Karageorghis, 1976: 72-94), que ha sido interpretada como evidencia de la práctica de cultos en honor de dioses vinculados a la metalurgia -explotación de las minas, fundición o comercio del cobre--, prácticas que en Kition estarian ya presentes en el siglo xIII a.C. y que en Enkomi serían algo más tardias. 


\section{BIBLIOGRAFÍA}

Astrom, P., 1972: The Late Cypriote Bronze Age. Architecture and Pottery. S.C.E., Vol. IV, 1C, Estocolmo.

Clerd, G., Karageorghis, V. et Al., 1976: Fouilles de Kition II. Dpt. of Antiquities, Republic of Cyprus, Nicosia.

Gessell, G. C., 1985: Town, Palace and House Cult in Minoan Crete, SIMA, LXVII, Goteborg.

GJeRSTAD, E., LINDROS, J. et Al., 1934: The Swedish Cyprus Expedition: Finds and Results of the Excavations in Cyprus. Vol. I, Estocolmo.

- 1935: The Swedish Cyprus Expedition: Finds and Results of the Excavations in Cyprus, 1927-1931, Vol. II, Estocolmo.

KARAGEORGHIS, V., 1968: "Chronique des fouilles et decouvertes à Chypre en 1967», B.C.H., 92 págs. 302 y ss.

- 1970: "Chronique des fouilles et decouvertes à Chypre en 1969", B.C.H., 94, págs. 290 y ss.

- 1971: "Chronique des fouilles et decouvertes archéològiques à Chypre en 1970", B.C.H., 95, 1971, págs. 335 y ss.

- 1972: "Chronique des fouilles et decouvertes archéològiques à Chypre en 1971 », B.C.H., 96, 1972, págs. 1.005 y ss.

- 1973: "Contribution to the Religion of Cyprus in the XIII and XII Centuries B.C.". Acts of the International Archeological Symposium "The Mycenaeans in the Eastern Mediterranean", págs. 105 y ss., Nicosia.

- 1976: Kition. Mycenaean and Phoenician Discoveries in Cyprus. Thames \& Hudson, Londres.

- 1980: "Chronique des fouilles et decouvertes archéològiques à Chypre en 1979", B.C.H., págs. 761 y ss.

- 1982: Cyprus from the Stone Age to The Romans. Thames \& Hudson, Londres. 
Karageorghis, V. y Demas, M., 1981: “Excavations at Pyla Kokkinokremos 1981 (First Preliminary Report).» RDAC, págs. 135 y ss.

Karageorghis, V., Demas, M. y Kling, B., 1982: “Excavations at Maa Palaeokastro 1979-1982. A preliminary Report.» $R D A C$, págs. 86 y SS.

LoulloupIS, M., 1973: “Mycenaeans Horns of Consacration in Cyprus." Acts of the International Archaeological Symposium "The Mycenaeans in the Eastern Mediterranean", págs. 68 y ss., Nicosia.

MAIER, F. G., 1973: "Evidence for Mycenaean settlement at Old Paphos», Acts of International Archaeological Symposium "The Mycenaeans in the Eastern Mediterranean", págs. 68 y ss.

- 1978: "Ausgräbungen in Alt Paphos. Neunter Vorläufiger Bericht: Grabunskampagne 1976», Arch. Anzeiger, Heft 3, Berlín.

- 1979: "The Paphian Shrine of Aphrodite and Crete", Acts of the International Archaeological Symposium "The Relations between $\mathrm{Cy}$ prus and Crete ca. 200-500 B.C., págs. 228 y ss., Nicosia.

Masson, O., 1973: “Remarques sur les cultes chypriotes à l'époque du Bronze Recent», Acts of the International Archaeological Symposium "The Mycenaeans in the Eastern Mediterranean", págs. 110 y ss., Nicosia.

Plat du Taylor, J., Birmingham, J. M. et Al., 1957: Myrtou-Pighades. A Late Bronze Age Sanctuary in Cyprus. Dpt. Antiquities Ashmoleam Museum, Oxford.

Poyato Holgado, C. y Vázquez Hoys, A.: Introducción a la Arqueología $\star \star \star \star$ : El mundo minoico. Madrid, Ed. Ramón Areces. En prensa.

Rutkowski, B., 1986: The Cult Places of the Aegean. Yale University Press, N. Haven-Londres.

Vázquez hoys, A. y Poyato Holgado, C.: Los oráculos y su poder. El sueño de Jacob, el poder oracular de Herakles y el sueño de César. Coincidencias o empresas comerciales. Homenaje a J. M. Blázquez. Dpto. $H^{a}$ Antigua, Universidad Complutense de Madrid (en prensa).

VázQuez, Hoys, A. y Poyato Holgado, C.: L'activité comerciale du temple tyrien et son expansión maritime, un posible precedent biblique. Xth International. Colloquium: Phoenicia and the Bible. Archaeology, History, Epigraphy. Universidad Católica de Lovaina, febrero 1990 (en prensa).

Yavis, C. G., 1949: Greek Altars. Origins and Typology. St. Louis University Press, Missouri. 